\title{
Pentagonal Shaped Multi-Wideband Antenna for Indoor Wireless Communication
}

\author{
Pratap N. Shinde \\ Dept. of Electronics \&Telecommunication \\ Sinhgad Academy of Engineering, Pune, India
}

\begin{abstract}
A coplanar waveguide feed pentagonal shape band- notched monopole antenna is proposed for multi-wideband operation. To avoid the potential interference of existing narrow bands with ultrawideband, the open ended slots embedded in monopole radiating surface and thin ground plane are used as notch filter centered at $3.5 \mathrm{GHz}$ and $7.5 \mathrm{GHz}$ respectively. The open circuit semi-spirally extended thin ground plane is designed for rejection of the band centered at $5.2 \mathrm{GHz}$. The Bandwidth is enhanced by suppressing the spurious notch band. The four operating bands developed due to the insertion of three notch bands, have $-10 \mathrm{~dB}$ impedance bandwidth of $594 \mathrm{MHz}$ (2.714-3.308 GHz), $990 \mathrm{MHz}$ (3.952$4.942 \mathrm{GHz}), 1.12 \mathrm{GHz}(5.964-7.088 \mathrm{GHz})$ and $3.1 \mathrm{GHz}(8.25-$ $11.35 \mathrm{GHz}$ ) respectively. Group delay less than $1 \mathrm{~ns}$ across all operating bands show good signal integrity. The radiation patterns in the H-plane are omnidirectional with low cross polarization levels and bidirectional in the E-plane. The simulated and measured results are in good agreement.
\end{abstract}

\section{Keywords}

Pentagon, full band, multi-wideband, notch filter, open ended slot.

\section{INTRODUCTION}

Federal Communications Commission (FCC) resolution on $14^{\text {th }}$ February 2002, recommended a $7.5 \mathrm{GHz}$ bandwidth ranging from $3.1-10.6 \mathrm{GHz}$ for ultrawideband (UWB) communication systems [1]. The UWB system has attracted significant research attention of academic communities as well as wireless telecommunication industries in the past few years. An important part of the UWB system is the antenna. Compact size, conformal, low cost, ease of integration, large bandwidth, high data rate, low output power, simple structure and interference rejection are the desired features of UWB antennas. The monopole antennas with UWB characteristics [2], [3], [4], [5], [6] are studied. The antennas were designed using radiating patch of standard geometrical shape and ground plane of trapezoidal shape. The antennas geometry with staircase shape [7], [8], [9] has shown wide bandwidth operation with good impedance match. The UWB spectrum possesses the potential interference of existing narrow band applications. In this regard some recent UWB antenna designs [10], [11], [12], are studied, that rejects the interference of very closely associated narrow bands. The geometry of these antennas became very complex due to increase in band-notch structure per rejection band.

On the rise of compact miniaturized UWB antennas, this paper presents a design of coplanar waveguide (CPW) feed pentagon shaped band-notched multiband monopole antenna. It discusses multiple use of semi-spiral shaped extended thin ground plane. The feeding at side length of radiating surface than at its vertex [13], [14] is an advantage of proposed

\author{
Jayashree P. Shinde \\ Dept. of Electronics \&Telecommunication \\ Sinhgad Academy of Engineering, Pune, India
}

antenna. Such type of feeding minimizes the need of ground plane alteration for wideband operation. The pentagonal shaped monopole antennas with feed at vertex [15], side length [16], [17] and alteration in ground plane, are studied for wideband operation. The vertical rectangular open ended slot in radiating surface of proposed monopole antenna can be a substitute for two semicircular slots [18] to achieve band-notch characteristics in X-band. Recently reported compact planar antennas for multiband operation are also studied [19], [20].

\section{FULL BAND ANTENNA DESIGN}

Figure 1 shows the geometry and photograph of proposed pentagon shaped band-notched multi-wideband monopole antenna. The proposed antenna is designed using low cost FR4 substrate of size $\mathrm{W} \times \mathrm{L}: 32 \mathrm{~mm} \times 22 \mathrm{~mm}$, thickness 1.6 $\mathrm{mm}$, relative permittivity 4.4 and loss tangent $(\tan \delta) 0.02$. The full band antenna design consist of pentagonal shaped monopole with side length $S$, coplanar thin ground plane of height $h_{1}$, and impedance matching stubs $s_{1}$ and $s_{2}$. The pentagonal shaped monopole antenna is excited by a $50 \Omega$ CPW feed line of width $w_{f}$ via impedance matching stub $s_{l}$ and $s_{2}$ of dimensions $0.64 \mathrm{~mm} \times 6 \mathrm{~mm}$ and $0.5 \mathrm{~mm} \times 4.4 \mathrm{~mm}$ respectively. These stubs minimize input impedance variation over wide operating bandwidth. The thin rectangular coplanar ground plane forms the distributed matching network with the monopole, which results in the wideband characteristics. At $w_{f}=2.8 \mathrm{~mm}, S=9.522 \mathrm{~mm}, h_{l}=4.4 \mathrm{~mm}$ and $4.45 \mathrm{~mm}$, wide bandwidth of $8.60 \mathrm{GHz}(2.80-11.40)$ is generated by overlapping the closely spaced resonant modes. At optimal parameter of $w_{f}=2.6 \mathrm{~mm}$ and $h_{1}=4.35 \mathrm{~mm}$, antenna bandwidth closer to FCC specification of $7.65 \mathrm{GHz}(2.8$ $10.45 \mathrm{GHz}$ ) is achieved, which corresponds to fractional bandwidth of $115.47 \%$. Full band antenna can be termed as pentagonal shaped compact ultrawideband monopole antenna (PSCUMA). Figure 4 shows the reflection coefficient $\left(S_{11}\right)$ of full band antenna.

\section{MULTIBAND ANTENNA DESIGN}

The $7.65 \mathrm{GHz}$ wide bandwidth of full band antenna is segmented into four wide operating bands for various wireless applications. It is achieved by generating multi-resonance using band-notch structures, which are designed at centre rejection frequencies of $3.5 \mathrm{GHz}, 5.2 \mathrm{GHz}$ and $7.5 \mathrm{GHz}$. A pair of open ended L- shaped slots is etched in the thin ground plane as $3.5 \mathrm{GHz}$ notch structure. The length of L-shaped slot is optimized at $13.45 \mathrm{~mm}$, to achieve band-notch at $3.5 \mathrm{GHz}$. The length $13.45 \mathrm{~mm}$ is approximately about a quarter of the guided wavelength $\left(\lambda_{g} / 4\right)$, calculated at a frequency of 3.5 GHz. In the design, the guided wavelength is $\lambda_{g}=\lambda_{0} / \mathcal{}_{\varepsilon_{e f f}}$ and $\varepsilon_{\text {eff }}=\left(\varepsilon_{r}+1\right) / 2$, where $\lambda_{0}$ is the free space wavelength. 


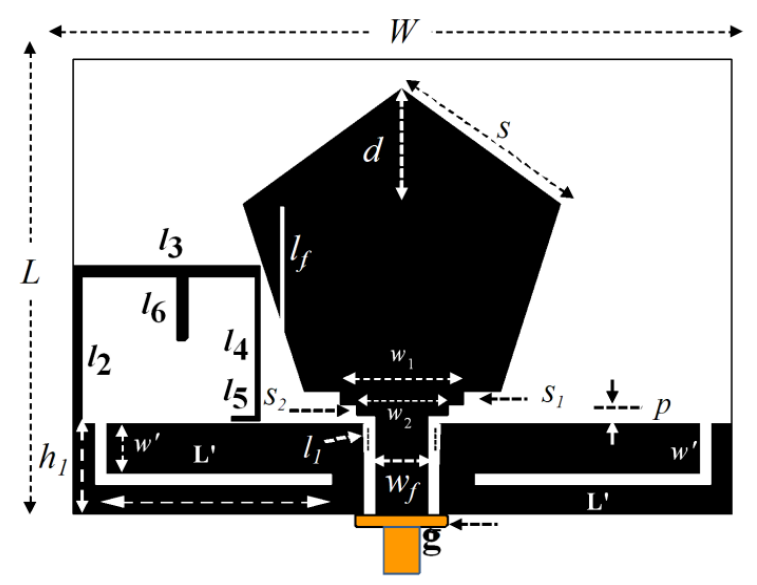

(a)

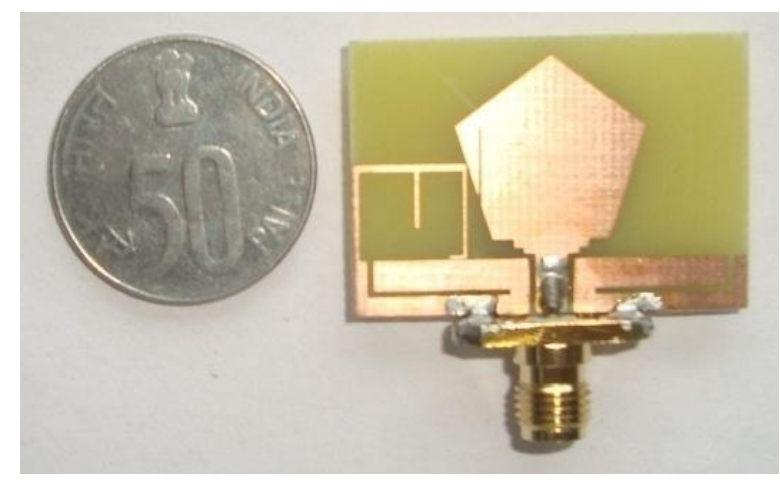

(b)

Fig 1: (a) Geometry of pentagon shaped multi-wideband pentagon antenna (b) photograph of fabricated antenna

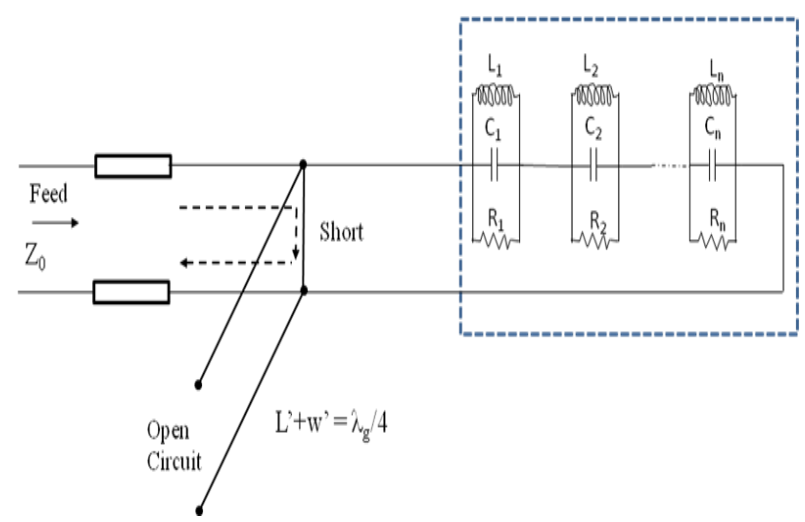

Fig 2: Equivalent circuit at $3.5 \mathrm{GHz}$ for the band-notched antenna with quarter wavelength $L$-shaped slot resonator

The $3.5 \mathrm{GHz}$ notch frequency is determined by (1). Where $c$ is the speed of light in the free space $\varepsilon_{r}$ is the dielectric constant, and $\left(w^{\prime}+L^{\prime}\right)=13.45 \mathrm{~mm}$ is the length of L-shaped slot.

$$
f_{3.5 \mathrm{GHz}}=\frac{C}{4\left(W^{\prime}+L^{\prime}\right) \sqrt{\epsilon_{\text {eff }}}}
$$

The equivalent circuit of the L- shaped slot ground plane is viewed as a parallel combination of equivalent inductor, capacitor and ground resistance. It exists at open circuit node point as shown in Figure2 as RLC lump circuit of a $3.5 \mathrm{GHz}$ band-notch. It explains the working of the notch structure along with control of the notch bandwidth with its center frequency. It is commonly known that, when the current propagates along the edge of the slot, an inductance must be considered in the model. The length and slot width of Lshaped resonator represents inductance and capacitance respectively. The capacitor is presented by a narrow slot width. Increasing the length of the slot or decreasing the width of the slot is equivalent to increase in the capacitance value in the parallel LC circuit. On the other hand, the inductor value will also increase with the increase in length of L- shaped slot. Therefore the notch bandwidth and the center frequency depend on the value of the equivalent capacitor, and inductor. The increase in the slot length will lower the notch resonant frequency with decrease in the bandwidth as the inductor and capacitor value increases proportionally. It is verified by the VSWR curves as shown in Figure 3(a). It indicates that the bandwidth and resonant frequency of rejection band is controlled by variation in slot length $L^{\prime}$.

The semi-spirally extended thin ground plane is designed for notch band at $5.2 \mathrm{GHz}$. The ground plane length $L^{\prime}\left(L^{\prime}=l_{2}+l_{3}\right.$ $+l_{4}$ ) except $l_{5}$ plays the role of ground resonator along with the pentagonal shaped radiator. With the inclusion of length $l_{5}$, the length $L "\left(L "=l_{3}+l_{4}+l_{5}\right)$ acts as an open circuited stub. In the absence of length $l_{2}$, the length $L$ " acts as a parasitic patch. The length $L$ " acts as notch element and its length is about half that of the guided wavelength $\left(\lambda_{g} / 2\right)$, calculated at notch frequency $5.2 \mathrm{GHz}$. The notch frequency at $5.2 \mathrm{GHz}$ is determined by (2). Calculated value of the notch frequency by (2) is $5.27 \mathrm{GHz}$ and that of the simulated one is 5.2 GHz. From Figure 3(b) it is observed that with an increase in $l_{5}$, the notch frequency shifts towards the lower frequency with VSWR more than 4.

$$
f_{5.2 \mathrm{GHz}}=\frac{C}{2\left(l_{3}+l_{4}+l_{5}\right) \sqrt{\frac{\left(\frac{\epsilon+1)}{2}\right.}{2}}}
$$

The band-notch at $7.5 \mathrm{GHz}$ is achieved by embedding an open ended rectangular slot in the monopole radiating surface, as shown in Figure1 (a). The open ended rectangular slot has a length of $l_{f}=6.1 \mathrm{~mm}$ and is about a quarter of the guided wavelength $\left(\lambda_{g} / 4\right)$ calculated at a notch frequency $7.5 \mathrm{GHz}$. In the design, the guided wavelength is $\lambda_{g}=\lambda_{0} / \mathcal{\varepsilon}_{\text {eff }}$ and $\varepsilon_{\text {eff }}=$ $\left(\varepsilon_{r}+1\right) / 2$. The peripheral length of the slot is $13.27 \mathrm{~mm}$. The open ended vertical slot has infinite impedance at the open end. At $7.5 \mathrm{GHz}$, the vertical open ended slot is terminated in a short circuit, which results in lowered radiation by the antenna. As the $d$ increases, effective open ended slot length decreases. It is observed that the length $l_{f}$ of the vertical slot determines the centre frequency of notch band as well as the notch bandwidth. Figure 3(c) shows the VSWR of the antenna with variation in the open ended slot width. It is seen that, with increase in the slot width from $0.3 \mathrm{~mm}$ to $1.4 \mathrm{~mm}$, notch frequency shifts from $7.6 \mathrm{GHz}$ to $7 \mathrm{GHz}$ respectively.

\section{RESULTS AND DISCUSSION}

The optimal parameters of the triple notched PSCUMA are $W$ $=32 \mathrm{~mm}, L=22 \mathrm{~mm}, h_{l}=4.35 \mathrm{~mm}, w_{f}=2.6 \mathrm{~mm}, g=0.5 \mathrm{~mm}$, $S=9.52, p=0.45 \mathrm{~mm}, s_{1}=0.64 \mathrm{~mm}, s_{2}=0.5 \mathrm{~mm}, l_{l}=1.85$ $\mathrm{mm}, L^{\prime}=11 \mathrm{~mm}$ and $w^{\prime}=2.45 \mathrm{~mm}, l_{2}=7.15 \mathrm{~mm} \mathrm{l}_{3}=9.1 \mathrm{~mm}$, 


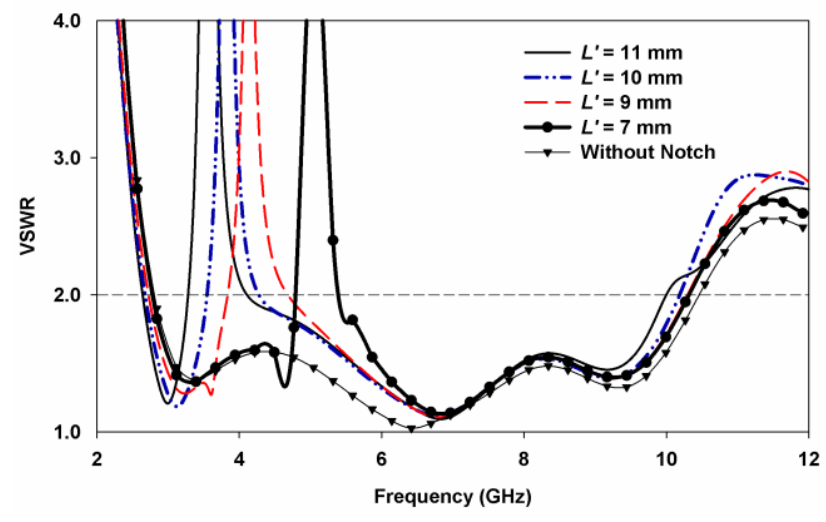

(a)

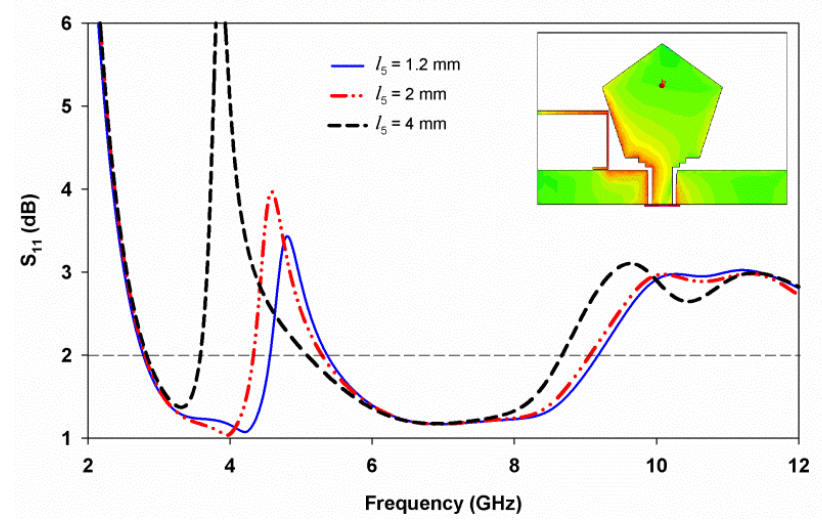

(b)

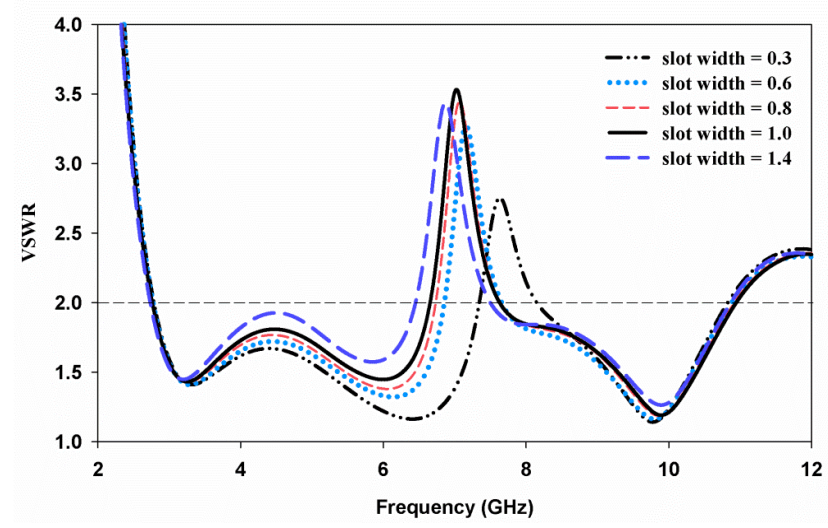

(c)

Fig 3: VSWR comparison of PSCUMA with individual notch filter at a time (a) pair of L-shaped slots for bandnotch at 3.5 GHz (b) semi-spirally extended thin ground plane for notch band at 5.2 GHz (c) open ended rectangular slot for notch band at $7.5 \mathrm{GHz}$

$l_{4}=7 \mathrm{~mm}$ and $l_{5}=1.2 \mathrm{~mm}, l_{f t}=6.1 \mathrm{~mm}$. Its reflection coefficient is shown in Figure 4. The open ended band-notch structure segments the $7.65 \mathrm{GHz}$ wide bandwidth of the PSCUMA into four operating bands. The resonating frequencies of these bands are $3 \mathrm{GHz}, 4.6 \mathrm{GHz}, 6.6 \mathrm{GHz}$ and $10.4 \mathrm{GHz}$ with an impedance bandwidth $594 \mathrm{MHz}, 990 \mathrm{MHz}$, $1.12 \mathrm{GHz}$ and $3.1 \mathrm{GHz}$ respectively. Three notch-bands generated are centred at $3.5 \mathrm{GHz}, 5.2 \mathrm{GHz}$ and $7.5 \mathrm{GHz}$ and provides notch bandwidth of $644 \mathrm{MHz}, 1.022 \mathrm{GHz}$ and 1.16 GHz respectively.

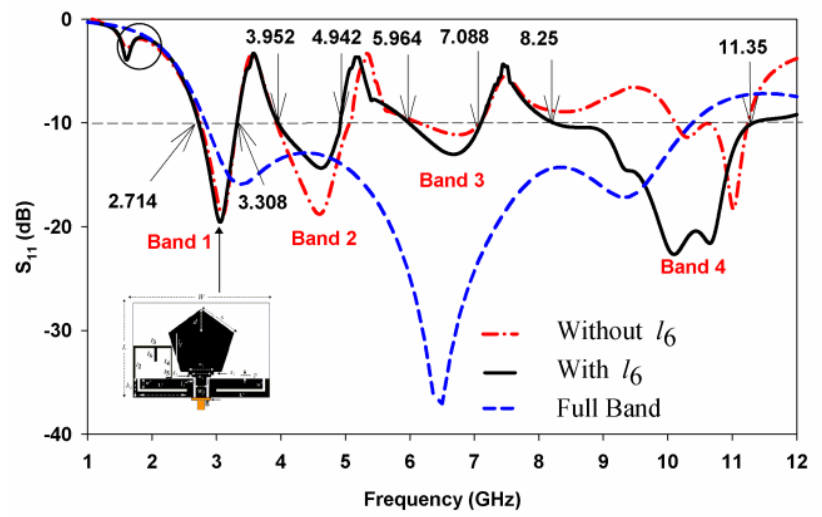

Fig 4: Simulated reflection coefficient of proposed multiwideband antenna

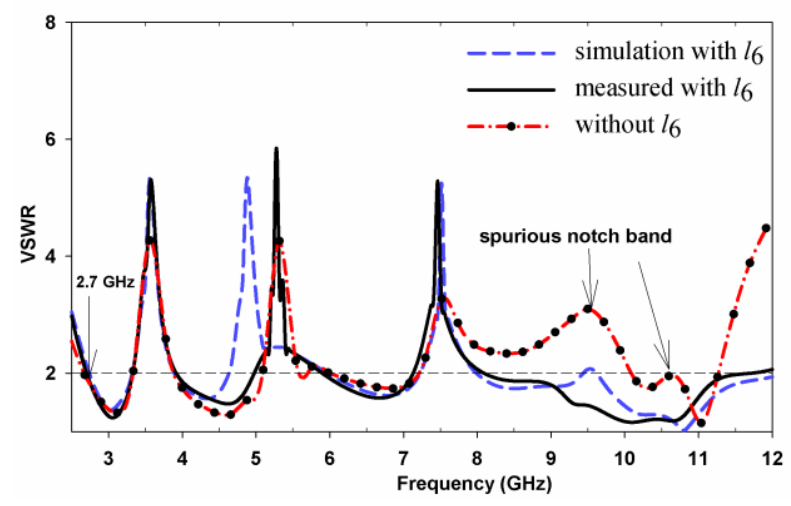

Fig 5: Measured and Simulated VSWR of proposed multiwideband antenna

The $l_{6}$ strip of $4.5 \mathrm{~mm} \times 0.3 \mathrm{~mm}$ dimension is included in the semi-spiral extended ground plane as shown in Figure 1(a). Due to $l_{6}$ the change in the capacitance and inductance of input impedance will occur. Figure 5 shows the VSWR of the antenna with and without $l_{6}$. It is observed that without $l_{6}$, the spurious notch is located at three times the centre notch frequency of the first notch band. With the inclusion of $l_{6}$, spurious notch-bands are reduced considerably and the bandwidth of the fourth operating band is improved by 1.13 GHz. Thus the full band antenna bandwidth $7.65 \mathrm{GHz}(2.8-$ $10.45 \mathrm{GHz}$ ) is segmented into multiband. The proposed multiwideband antenna can be useful for various indoor wireless devices such as wireless DVD player, Camcorder projectors and HDTV (high-definition television).

From Figure 6, the antenna gain remains constant over the operating bands, while it reduces at respective notch bands. From band 1 to band 4, the individual operating band gain is $5.32 \mathrm{dBi}, 2.53 \mathrm{dBi}, 3.01 \mathrm{dBi}$, and $2.9 \mathrm{dBi}$ respectively. The advantage of proposed antenna over the vertex feed antennas [13 - 14] is that, ground plane alteration is not required to achieve UWB. The performance comparison between the proposed antenna and some pentagonal shaped monopole antenna is summarised in Table 1 . The size reduction of $56 \%$, $71 \%$ and $75.72 \%$ with respect to substrate dimension is achieved compared with the reference pentagon shaped monopole antennas discussed in [15-17] respectively. Also it 
is observed that gain of proposed antenna is almost constant across operating bands and more than reference antennas.

Table1.Comparison between proposed and published antennas

\begin{tabular}{|c|c|c|c|}
\hline Reference & $\begin{array}{l}\text { Impedance BW, } \\
\left(f_{2}-f_{1}\right) \mathrm{GHz}\end{array}$ & $\begin{array}{l}\text { Gain } \\
(\mathrm{dBi})\end{array}$ & $\begin{array}{l}\text { Size } \\
\left(\mathrm{mm}^{2}\right)\end{array}$ \\
\hline [13] & $\begin{array}{l}0.71,(2.14-2.85) \\
0.79,(3.29-4.08) \\
1.07,(5.02-6.09) \\
\text { (Triple band nature) }\end{array}$ & $1.7-4.13$ & $40 \times 40$ \\
\hline [15] & $8.9, \quad(3.1-12)$ & 2.5 & $45 \times 54$ \\
\hline [16] & $18.11,(2.39-20.5)$ & $2-6$ & $58 \times 50$ \\
\hline [17] & $9.8, \quad(3.1-12.9)$ & 3.09 & $44 \times 30$ \\
\hline $\begin{array}{l}\text { Proposed } \\
\text { Antenna }\end{array}$ & $\begin{array}{l}7.65,(2.8-10.45) \\
(\mathrm{UWB}) \\
0.594,(2.714-3.308) \\
0.99,(3.952-4.942) \\
1.124,(5.964-7.088) \\
3.1,(8.25-11.35) \\
\text { (Multiband) }\end{array}$ & $2.9-5.32$ & $32 \times 22$ \\
\hline
\end{tabular}

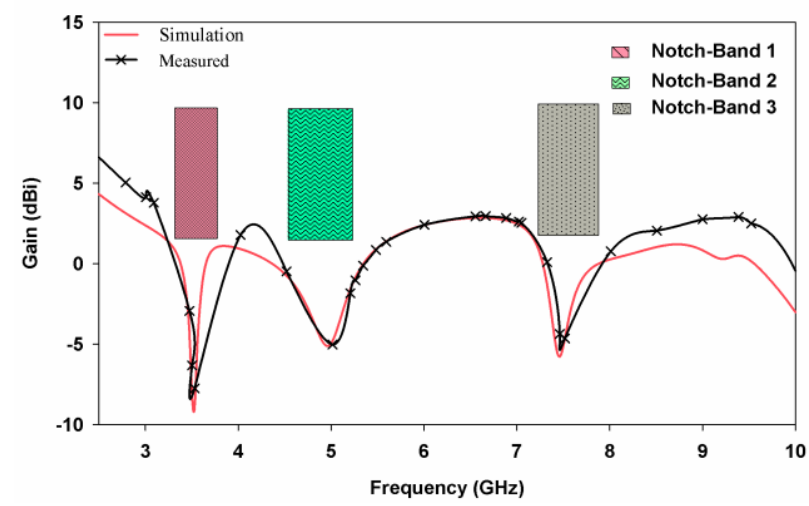

Fig 6: Measured and simulated gain of proposed antenna

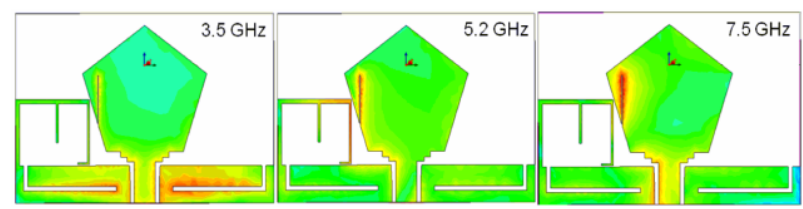

Fig 7: Current distribution at notch frequencies $3.5 \mathrm{GHz}$, $5.2 \mathrm{GHz}$ and $7.5 \mathrm{GHz}$

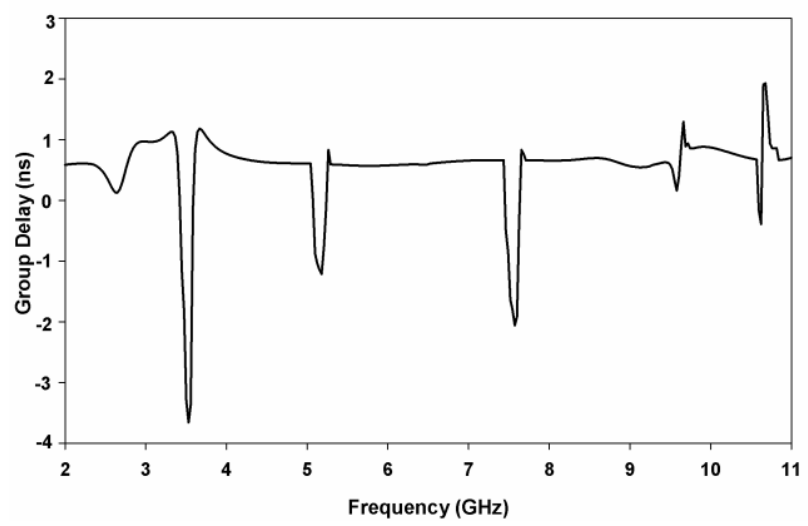

Fig 8: Group delay of the proposed antenna

Figure 7 shows the current distribution at various notch frequencies. The current is concentrated around the open ended slots and the semi spiral extended ground plane at respective notch frequencies. It is also found that there is a strong coupling between the vertical open ended slot and the semi-spirally extended thin ground plane at $5.2 \mathrm{GHz}$, which shows impedance mismatch. In wideband technology, group delay is more precise and useful measure of phase linearity of the phase response. Ideally, constant group delay is desired over the operating band. Figure 8 shows the simulated group delay of triple band-notched antenna. In the simulation setup the two identical band notched antennas are aligned face-toface each other. The group delay is obtained by exciting two identical antennas kept in the far field. The separation distance between them is $30 \mathrm{~cm}$. The variation of the group delay over the UWB band is less than $1 \mathrm{~ns}$, except at three notch bands. The group delay variation exceeds $3 \mathrm{~ns}, 1 \mathrm{~ns}$, and $2 \mathrm{~ns}$ at 3.5 $\mathrm{GHz}, 5.2 \mathrm{GHz}$ and $7.5 \mathrm{GHz}$ notch-bands respectively, which can deteriorate the phase linearity. However, in the unnotched frequency band, the group delay is almost flat, demonstrating good characteristics. This constant group delay feature demonstrates the triple band notched PSCUMA exhibit phase linearity at operating bands within the UWB spectrum.

The measured radiation pattern in the E-plane and H-plane are shown in Figure 9. It is observed that at $3 \mathrm{GHz}$, and $4.6 \mathrm{GHz}$, the radiation patterns in the $\mathrm{H}$-plane are omnidirectional while at $6.6 \mathrm{GHz}$ it is nearly omnidirectional. Also at these frequencies, E-plane radiation patterns are bidirectional with low cross polarization levels. This indicates the stable radiation performance for the first three bands. Gain is reduced at a higher frequency because of the side lobes. As the frequency increases, the radiation patterns become directional due to the excitation of the higher order current mode. 


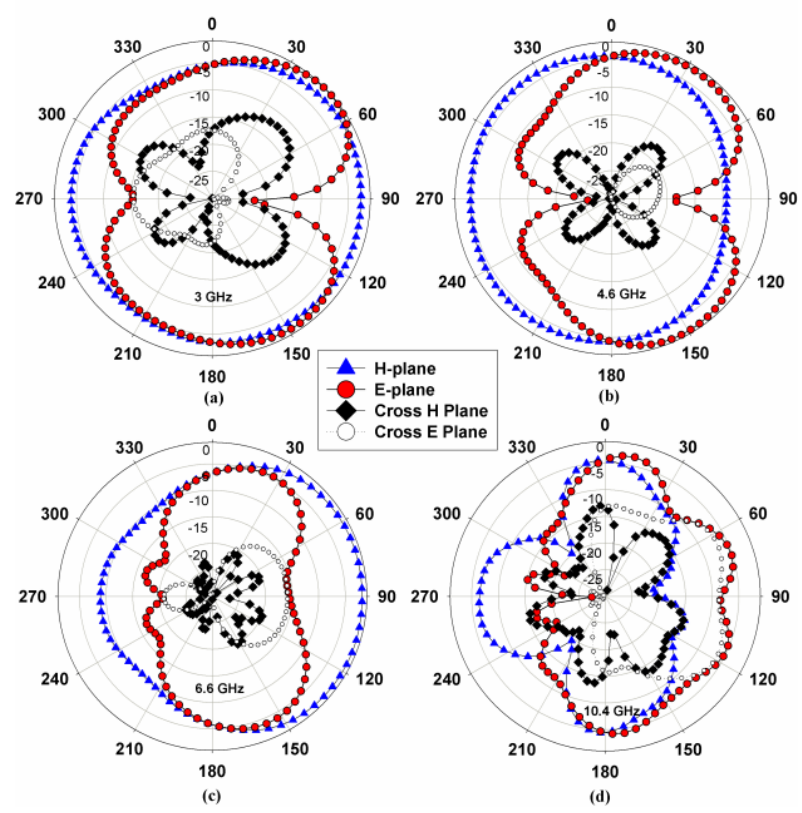

Fig 9: Measured radiation patterns of proposed antenna at (a) $3 \mathrm{GHz}$ (b) $4.6 \mathrm{GHz}$, (c) $6.6 \mathrm{GHz}$ and (d) $10.4 \mathrm{GHz}$ in Eplane (y-z plane) and $H-p l a n e ~(x-z$ plane)

\section{CONCLUSION}

This paper presents pentagonal shaped multi-wideband monopole antenna using band-notch at 3.5, 5.2 and 7.5 GHz. Semi-spirally extended thin ground plane plays multiple role like band-notch element, radiator and an element, which improves the impedance bandwidth of fourth operating band. The enhancement in bandwidth is achieved by efficiently reducing spurious notch across UWB. The size of the antenna is compact and can be easily integrated with monolithic microwave integrated circuits. The gain of the antenna over the four operating bands is $5.32 \mathrm{dBi}, 2.53 \mathrm{dBi}, 3.01 \mathrm{dBi}$ and $2.9 \mathrm{dBi}$ respectively. Constant group delay over the operating bands, except the notch bands, indicates phase linearity and good transient response. The proposed antenna can be a good candidate for various indoor wireless UWB devices such as high-speed cable replacement, including downloading pictures from digital cameras to PCs and wireless connections between DVD players, PC, Camcorder projectors and HDTV.

\section{ACKNOWLEDGMENTS}

We put our sincere thanks towards STES SAE management Pune, who have permitted for the development and use of Satellite Laboratory for antenna measurements.

\section{REFERENCES}

[1] Federal Communications Commission: First Report and order, revision of part 15 of the Commission's rule regarding ultra- wideband transmission system, 2002.

[2] Chu, Q.; Yang, Y.: A compact ultrawidwband antenna with $3.4 / 5.5 \mathrm{GHz}$ dual band-notched characteristics. IEEE Trans. Antennas Propag., 56 (12) (2008), 3637364.

[3] Liu1, W. C.; Kao, P.C.: CPW-Fed triangular monopole antenna for ultra-wideband operation. Microw. Opt. Technol. Lett., 47 (6) (2005), 580-582.

[4] Liang, X. L.; Zhong, S.S.; Wang, W.: Tapered CPW-Fed printed monopole antenna. Microw. Opt. Technol. Lett., 48 (7) (2006), 1411- 1413.
[5] Shinde, P.N.; Mishra, B. K.; Desingkar, N.: Design of defected ground compact UWB antenna. Int. Conf. on Microw. Antenna,Propag. and Remote sensing, India, 2012.

[6] Shinde, P.N.; Mishra, B. K.: Compact thin ground planar UWB antenna with dual band stop characteristics. Microw. Opt. Technol. Lett., 55 (5), 1045-1049, 2013.

[7] Peng, F.; Jiao, Y. C.; Zhu, Y.; Zhang, F.S.: Compact CPW-Fed monopole antenna and miniaturized ACS-fed half monopole antenna for UWB applications. Microw. Opt. Technol. Lett., 54 (7), 1605-1608, 2012.

[8] Gao, G.P.; Yang, M.K.; Niu, S.F.; Zhang, J.S.: Study of a novel U-shaped monopole UWB antenna by transfer function and time domain characteristics. Microw. Opt. Technol. Lett., 54 (6), 1532-1537, 2012.

[9] Wang, C.; Yan, Z.H.; Li, B.; Xu, P.: A dual bandnotched UWB printed antenna with $\mathrm{C}$-shaped and Ushaped slots. Microw. Opt. Technol. Lett., 54 (6), 14501452,2012

[10] Li, W. T.; Xiao, W. S.; Hei, Y. Q.: Novel planar UWB monopole antenna with triple band-notched characteristics. IEEE Antennas Wireless Propag. Lett., 8,1094-1098, 2009.

[11] Almalkawi, M.; Devabhaktuni, V.: Ultrawideband antenna with triple band-notched characteristics using closed-loop ring resonators. IEEE Antennas Wireless Propag. Lett., 10, 959-962, 2011.

[12] Xu, K.; Zhu, Z.; Li, H.; Huangfu, J.; Li, C.; Ran L.:, A printed single-layer UWB monopole antenna with extended ground plane stubs. IEEE Antennas Wireless Propag. Lett., 12, 237-240, 2013.

[13] Hsien,W. L.; Ku, C.H.; Yang, C.F.: Novel CPW-fed planar monopole antenna for WIMAX/WLAN application. IEEE Antennas Wireless Propag. Lett., 9, 240-243, 2010

[14] Mahdi, N.J.: Novel wideband planar fractal monopole antenna. IEEE Trans. Antennas Propag., 56 (12), 3844 3849,2008

[15] Moody, Robert A.; Sharma S. K.: Investigations on coplanar waveguide fed pentagon shape planar monopole ultra-wide bandwidth (UWB) antenna on foam substrate providing invariant radiation patterns., IEEE Antennas propag. Soc., Int. Sympo., 1-4, 2010.

[16] Shrivastava V.; Ranga Y.: Ultra wide band CPW-fed printed pentagonal antenna with modified ground plane for UWB applications", IET Int. Conf. on Wireless, Mobile and Multimedia Network, 1-8, 2008.

[17] Fattah,M. A. A.; Allam A. M. M. A.; Shoukry I. S.: Irregular pentagon monopole structured antenna for ultra-wideband communication systems, IEEE APS, Middle East Conf. Antennas and Propag. (MECAP), 1-4, 2010.

[18] Nguyen, T.D.; Lee, D.H.; Park H. C.: Design and analysis of compact printed tripple band-notched UWB antenna. IEEE Antennas Wireless Propag. Lett., 10, 403406, 2011.

[19] Shinde, P.N.; Mishra, B. K.: Design of triple band slot antenna for $802.11 \mathrm{a} / \mathrm{b}$ WLAN and upper UWB 
International Journal of Computer Applications (0975 - 8887)

Volume 180 - No.47, June 2018

application using pentagon tuning stub. Int. J. Microw. Opt. Technol., 8 (1), 11-17, 2013.

[20] Shinde, P.N.; Shinde, J. P.: Design of compact pentagonal slot antenna with bandwidth enhancement for multiband wireless applications. Elsevier's Int. J. of Electron Commun., 69, 1489-1494, 2015.

[21] 